\title{
Correspondence
}

\section{Selection of inquiry members}

Sir: I have no desire to step into the ring and try and referee ninety-three rounds of bare knuckle fighting between Dr Maden (Psychiatric Bulletin. August 1999, 23, 455-457) and Judge Fallon (Psychiatric Bulletin, August 1999, 23, 458-460) but the articles and correspondence regarding the Ashworth Inquiry raise some general concerns.

Those of us in what I hesitate to term the 'expert witness community' have faced an assault on our professional integrity and independence in the setting of the Woolf Reforms, with judges and lawyers at all levels making comments about bias in experts instructed by either side in an adversarial system. However, when it comes to inquiries, those involved seem to have a very different view of their own position. As I understand it, Judge Fallon and his colleagues were selected by the Government, given their terms of reference by the Government and of course are well paid by the Government. Where is the independence? If one says it rests in their professional integrity, then why does this not hold true for professionals acting as experts? Moreover, the Government and the bodies it delegates to are not disinterested authorities. The idea that the Government is not likely to select people for its inquiries who are likely to come to a view which is agreeable to the Government seems to me to be astonishingly naive, particularly in these days of viscous spin. Have any of these inquiries ever dealt with responsible politicians and senior civil servants in the same way as named professional staff?

The issue here is that of selection of inquiry members. If enquiry committees are even going to be perceived as independent surely the time has come for a truly independent authority, responsible to Parliament rather than the Government, with multiple representation and funding, to deal with public inquiries of all kinds. Obviously this is not a perfect solution but it has to be better than what we have currently.

Judge Fallon's criticism of Dr Maden and Professor Gunn is not desperately helpful. Senior colleagues in forensic psychiatry not only have a right, but also a responsibility, to speak out on such important issues. Consultants in the NHS have learned to become both wary and weary of marvellous reorganisations of their services.

Judge Fallon also fails to comment on the most important part of Dr Maden's assault on his committee, namely that it has presided over the professional pillorying or destruction of individuals without their having any opportunity to answer criticism or offer mitigation before publication. It's too late after. The College has been making appropriate noises about this issue, quite rightly, for some time now, but seems to have given up and now has joined in this wholly unjust way of treating its members and fellows. Dr Payne's letter requires a proper answer. Who at the College was responsible for the 'College's Comments' (Psychiatric Bulletin, August 1999, 23, 452-454)? Why was there no consultation? Can we have an assurance from our new President that the College will not act in this unjust and unfair way against individual psychiatrists in the future?

Duncan Veasey, Consultant Psychiatrist, Rectory Farm, East Chaldon Road, Winfrith Newburgh, $\mathrm{Nr}$ Dorchester, Dorset DT2 8DJ

\section{Cybertherapy}

Sir: I read with interest Thompson's paper on the Internet and its potential influence on suicide. (Psychiatric Bulletin, August 1999, 23, 449-451). Exposure to newsgroups advocating suicide is but one of the potential hazards of cyberspace; another is the increasingly prevalent practice of 'cybertherapy'.

A site of particular interest is the Cyberanalysis Clinic (http://www.cyberanalysis.com). This offers "a combination of the most effective elements of several schools of psychotherapy: cognitive-analytical therapy, client-centred therapy. Freudian psychoanalytical psychotherapy, transactional analysis and personal construct therapy". which the author asserts is "better online than on a couch", and suitable for a wide range of psychological problems. Prominent on the site is the author's advertisement of himself as "an Inceptor of the Royal College of Psychiatry (sic) of the UK".

Shapiro \& Schulman (1996) identified several legal and ethical pitfalls in the then nascent discipline of cybertherapy, including the unreliability of online assessment and the lack of evidence for efficacy of established therapies delivered over the Net, let alone more speculative techniques. These issues and others have been debated online (see the website of the International Society for Mental Health Online at http:// www.ismho.org/), but little in the way of reliable evidence on safety and efficacy is available. 